\title{
Research Paper: The Effectiveness of Group Social Work Intervention with Resolving the Problem of Reducing Suicidal Ideation in Qorveh City
}

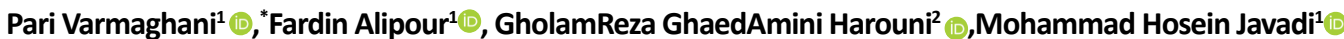

1. Department of Social work, University of Social Welfare and Rehabilitation Sciences, Tehran, Iran.

2. Social Welfare Management Research Center, University of Social Welfare and Rehabilitation Sciences, Tehran, Iran.

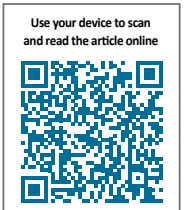

Cltition Varmaghani P, Alipour F, GhaedAmini Harouni Gh, Javadi Mh. [ The Effectiveness of Group Social Work Intervention With Problem Solving Approach on Reducing Female's Suicidal Thoughts in Qorveh (Persian)]. Archives of Rehabilitation. 2019; 20(3):286-297. http://dx.doi.org/10.32598/rj.20.3.286

doij http://dx.doi.org/10.32598/rj.20.3.286

Received: 11 Apr 2019 Accepted: 27 Aug 2019 Available Online: 01 Oct 2019

\begin{abstract}
Objective Suicide and suicidal behavior (suicidal ideation, suicidal plan, and suicidal act) as one of the major problems in the social and psychological health system is an important and significant issue around the world. In addition to personal and family damage, this phenomenon is also a social loss. Suicide is also a psychological and social problem which is one of the social traumas that requires immediate attention from relevant centers. Preventing suicide requires a comprehensive approach that includes physical, mental, social, and spiritual interventions, and the implementation of a wide range of psychosocial and social actions from social support and life skills training to counseling, follow-up, and treatment for mental disorders. It is possible to consider the action to reduce suicidal ideation using different approaches as part of preventive approaches to deal with this harm. Social workers as one of the specialized groups are closely associated with this problem. Their approach to have the more impact on reducing suicidal ideation is the problem-solving, which focuses on the individual and his decision-making problem, which is opposed to stigmatizing and instead emphasizes on abilities, promotion, and empowerment. The purpose of this study was to determine the effectiveness of group Social Work intervention with a problem-solving approach to reducing suicidal ideation in females referring to psychology and Social Work clinics.

Materials \& Methods In this study, quasi-experimental design with a randomized control group was used. The statistical population included all cases referring to Social Work clinics and counseling centers and clinics in Qorveh in 2017. Considering the importance of access to research samples and with the collaboration of psychiatric centers, 30 individuals willing to participate in the study and with suicidal ideation identified through a psychiatric interview, was divided into two experiment and control groups after giving written consent and using Block randomization method. A number of samples were dropped due to non-compliance with the intervention, of which 12 were in the experiment group and 11 were in the control group until the end of the intervention. The research tool was Beck Scale for Suicidal Ideation (BSSI) Questionnaire. In the experiment group, Social Work intervention with problem-solving approach and in the control group, training package of coping strategies was performed. All analyses were performed using SPSS software and covariance analysis was used to analyze the data.

Results The findings of the study showed that group Social Work intervention with a problemsolving approach statistically had a significant difference with the control group and could reduce the total score of suicidal ideation significantly, compared to the control group $(P<0.05)$. The findings of different analyzes in two groups showed that Social Work with problem-solving approach was more effective than the training package of coping strategies in reducing the suicidal ideation of women referring to clinics. The results of various analyzes in the two groups showed that the group
\end{abstract}

\section{* Corresponding Author:}

Fardin Alipour, PhD.

Address: Department of Social work, University of Social Welfare and Rehabilitation Sciences, Tehran, Iran.

Tel: +98 (21) 22180064

E-Mail: javadismh4@gmail.com 
Keywords:

Suicidal ideation, Group Social Work, Problem-solving approach work intervention had a significant effect on the four subscales: a desire for death, preparing for suicide, suicidal tendency, and the inhibitory factors or self-control $(P<0.001)$. Also, the power of a test (Cohen effect size), there are four major dimensions of suicidal ideation in the Social Work intervention compared to the training package of coping strategies.

Conclusion A comprehensive look at the social factors affecting suicide, especially group Social Work interventions that take a multilateral approach to a social problem, can reduce suicidal ideation and provide the basis for improving the quality of life of different groups of society. Regarding the nature of group Social Work with a problem-solving approach, it is very effective and promising and can also open a door to expanding Social Worker interventions in intervening in a suicidal crisis. 
This Page Intentionally Left Blank 


\section{اثربخشى مداخله مددكارى اجتماعى تروهى با رويكرد حل مسئله بر كاهش افكار خودكثى زنان در شهرستان قروه}

يرى ورمقانى' هـ "فردين علييور' 'ه، غلامرضا قائد امينى هارونى +ه، محمدحسين جوادى'

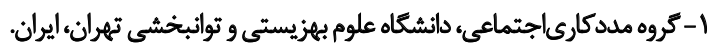

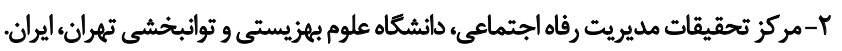

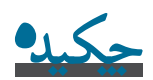

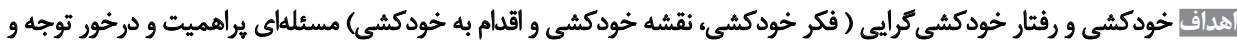

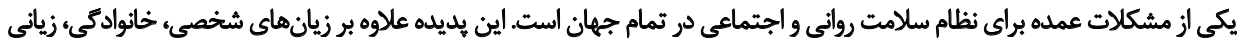

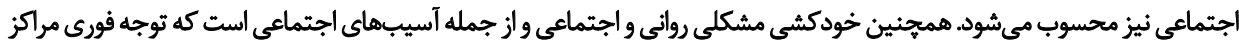

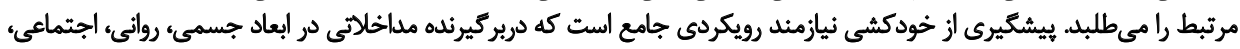

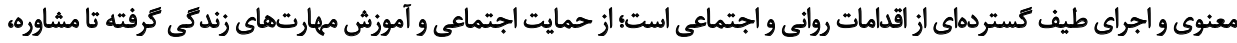

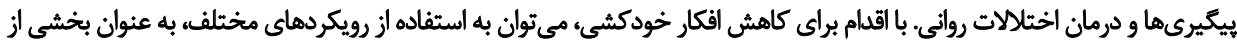

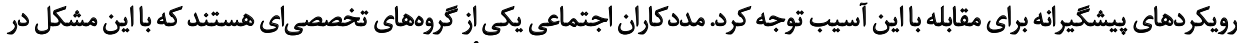

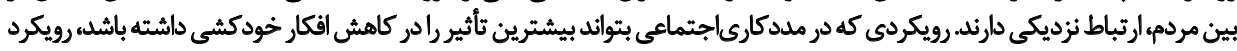

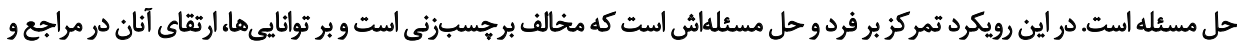

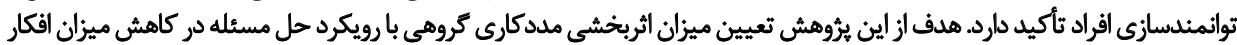

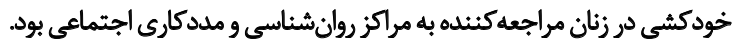

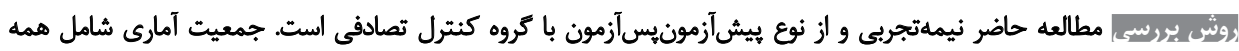

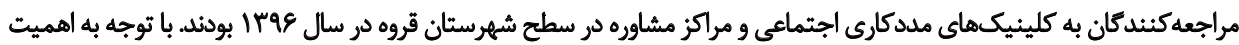

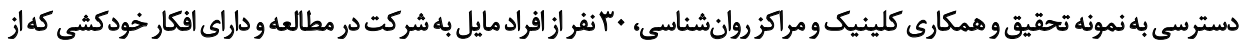

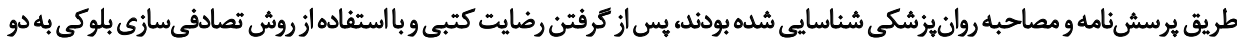

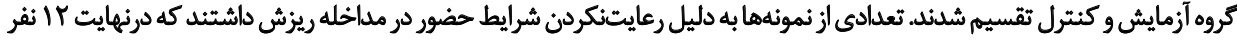

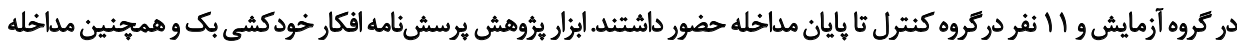

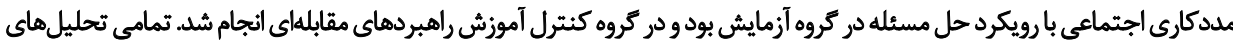

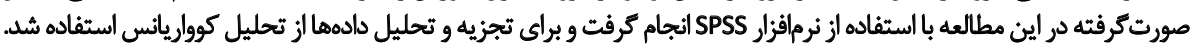

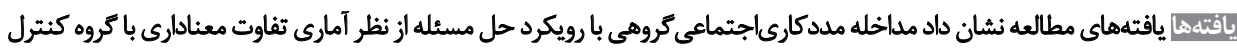

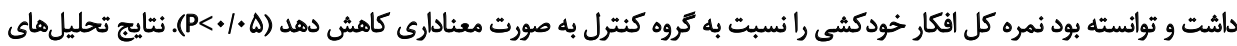

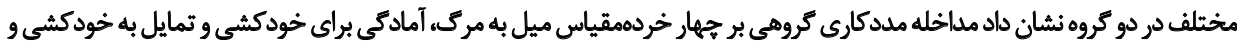

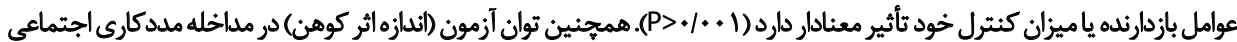

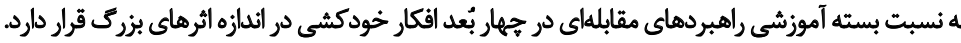

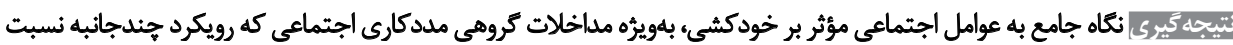

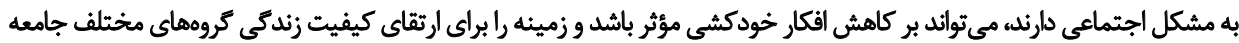

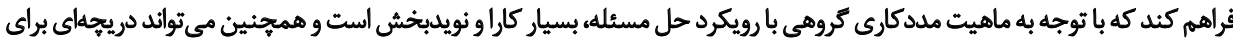

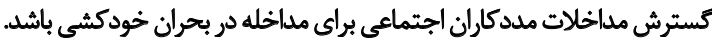

\author{
تاريخ دريافت: r ف فروردين \\ تاريخ بذيرش: ه· شهريو 1ه

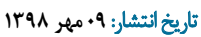

كليدوازٔهها:

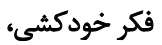

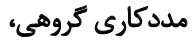
رويكرد حل مسئله 
اجتماعى در مداخلات و اقدامات بيشكيرانه از خودكشى بسيار مقلمه

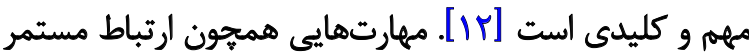

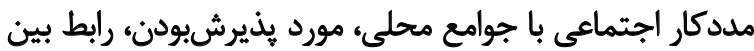

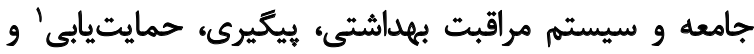

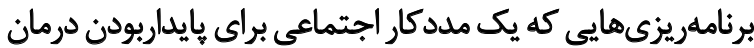

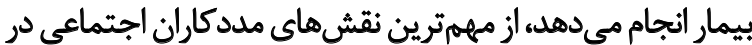

اين حوزه هستند [ب] إن.

يكى از مهمثترين عوامل خطر شناسايىشده در زمينه اقدام

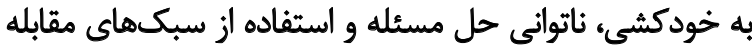

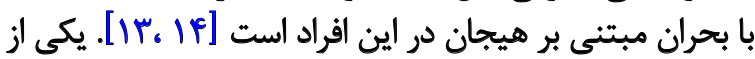

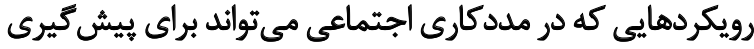

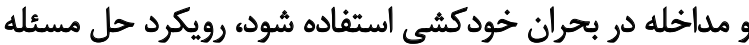

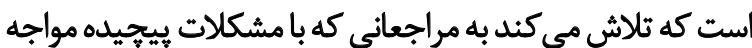

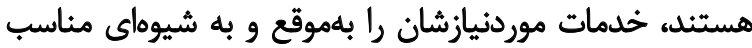

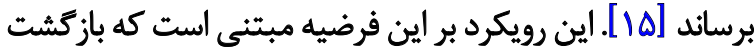

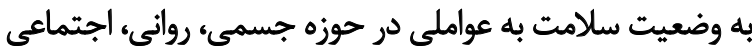

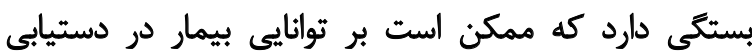

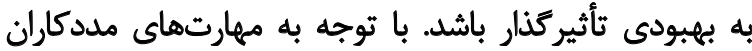

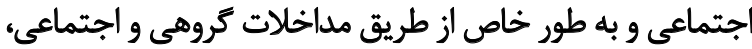

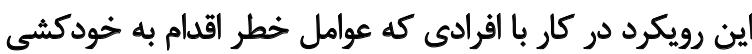

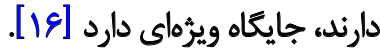

نتايج تحقيقات نشاندهنده اثربخشبودن مداخله حل

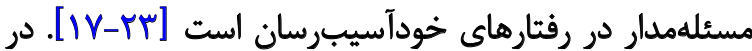

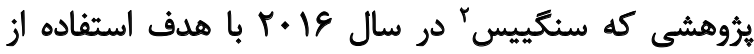

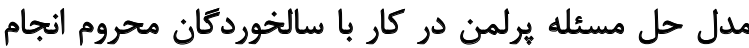

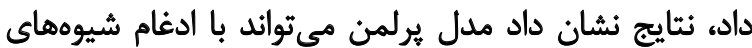

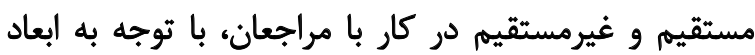

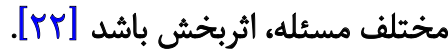

مطالعات مختلفى در حوزه بيشعَيرى از خودكشى انجام

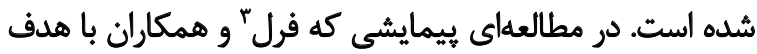

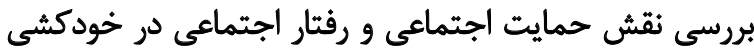

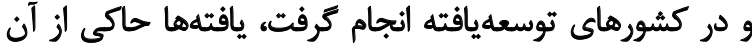

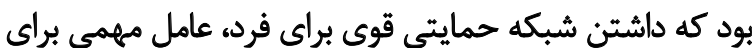

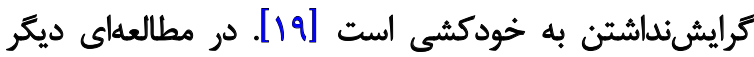

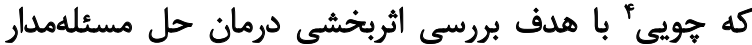

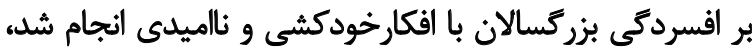

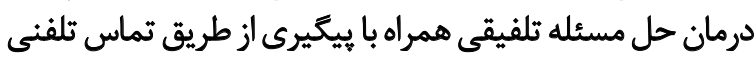

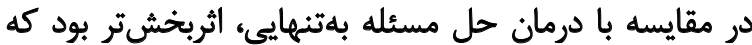

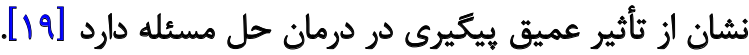

4. Choi NC

تغييرات سريع و بيجيديدى هاى جهان امروز به همراه

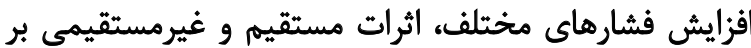

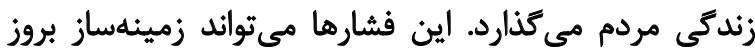

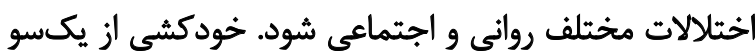

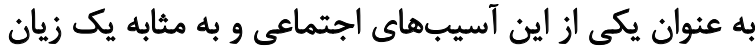

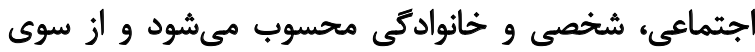

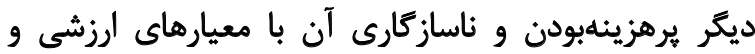

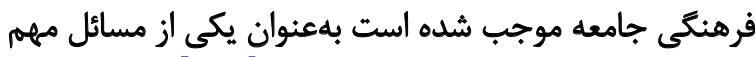

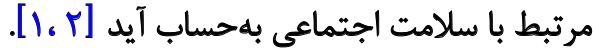

آمارهاى سازمان بهداشت جهانى نشاندهنده آن است كه

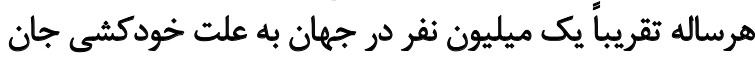

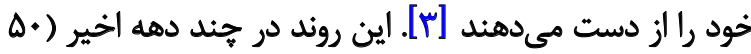

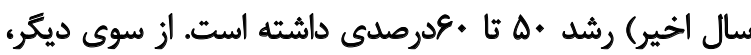

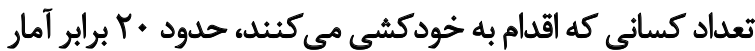

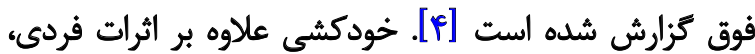

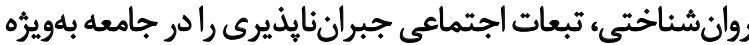

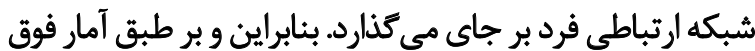

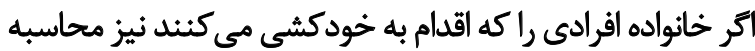

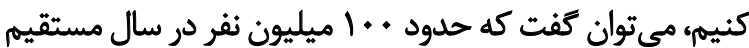
درير تبعات اقدام به خودكشى خداند [هان].

جه نظر ميرسد شيوع خودكشى در ايران نسبت به به آمار

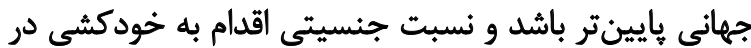

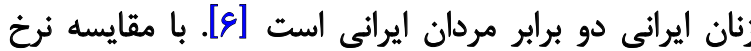

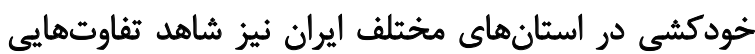

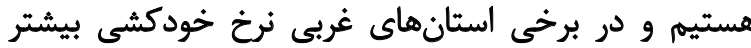

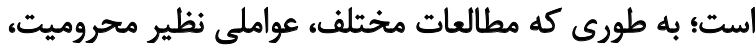

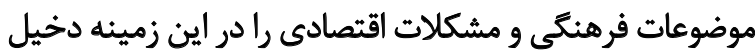

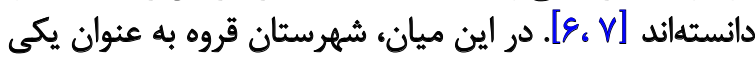

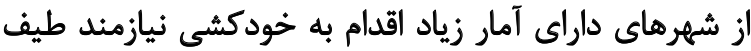

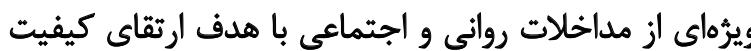

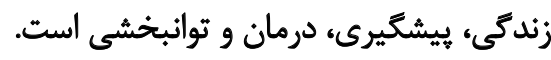

موفقيت برنامههاى ييشكيرى و درمان خودكشى نيازمند

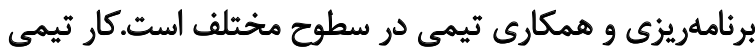

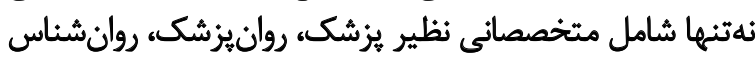

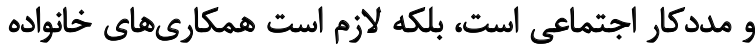

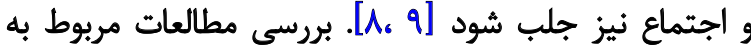

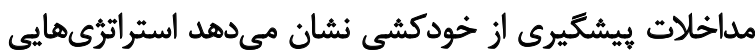

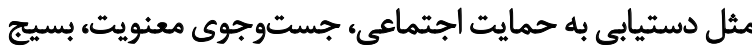

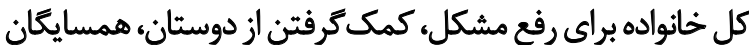

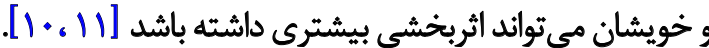
از سوى ديكر مطالعات مختلف نشان دادهاند نقش مددكاران 


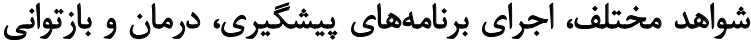

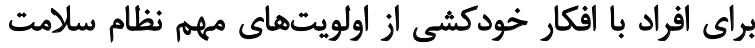

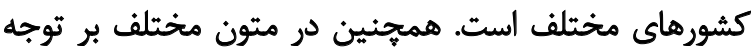

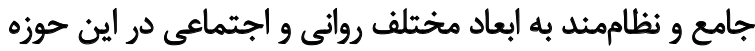

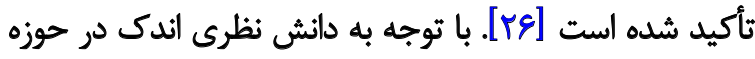

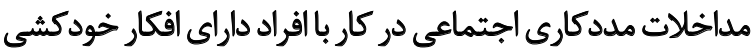

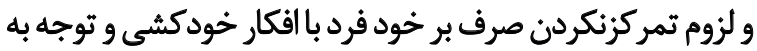
ابعاد فردى و اجتماعى مسئله، اين مطالعه تأثير اثربخشيى مدردي مداخله

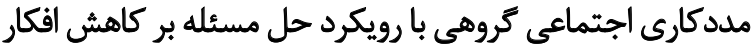

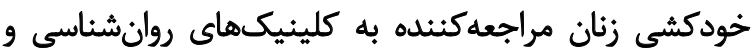
مددكارى اجتماعى شهرستان قروه را بررسى كرده است.

$$
\text { وروّن بروسى }
$$

يزوهش حاضر از لحاظ هدف، كاربردى و از لحاظ شيوه

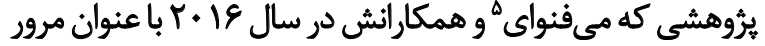

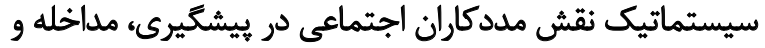

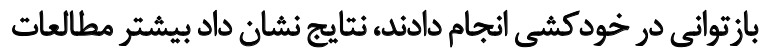

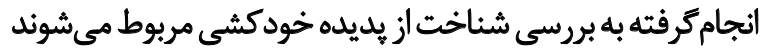

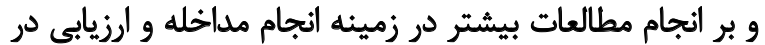
خودكشى براى مددكاران اجتماعى تأكيد كردند [ب]

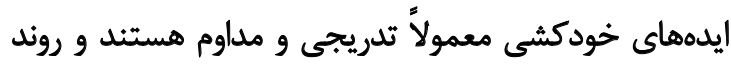

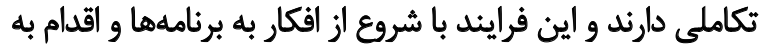

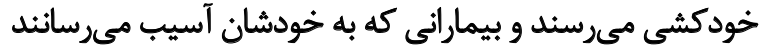

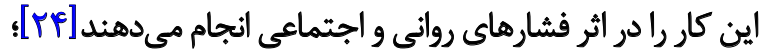

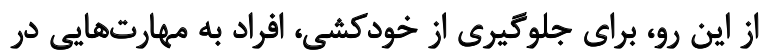

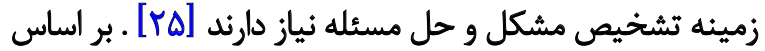

5. Myfanwy

جدول (. شرح بسته مداخله مددكارى اجتماعى با رويكرد حل مساله

\begin{tabular}{|c|c|c|}
\hline اهداف & محتواى جلسات & جلسات \\
\hline - & 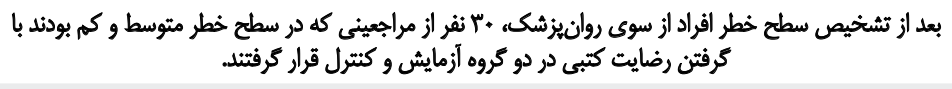 & قبل از مداخله كروهى \\
\hline آشنايع اوليه & 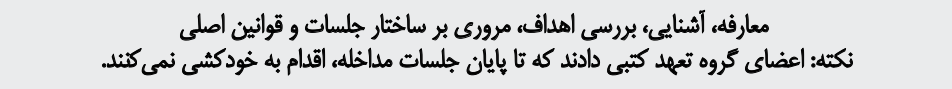 & جلسه اول مداخله كروهى \\
\hline شناسايع و تعريف مسئله (مرحله & 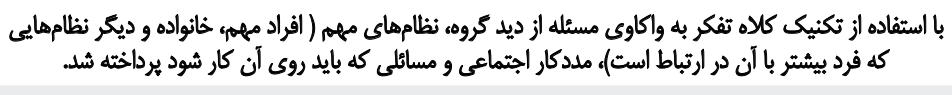 & جلسه دوم مداخله كروهى \\
\hline شناسايیى هدف (مرحله تماس) & 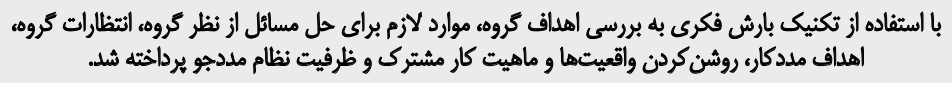 & جلسه سوم مداخله كروهى \\
\hline 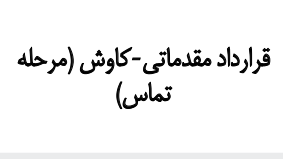 & 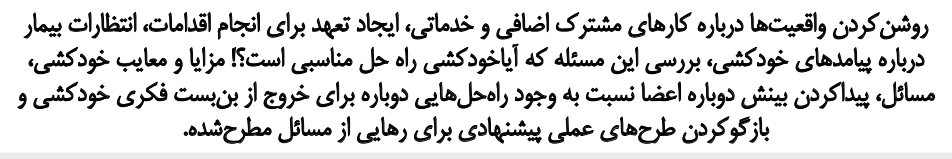 & جلسه جمارم مداخله كروهى \\
\hline 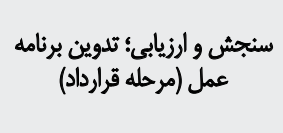 & 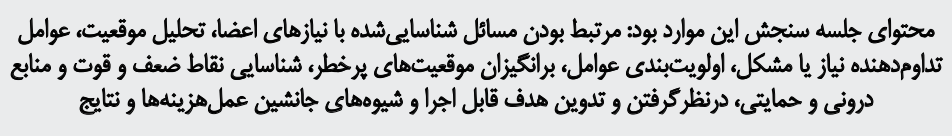 & جلسه ينجميم مداخله كروهى \\
\hline اجراى طرح (مرحله عمل) & 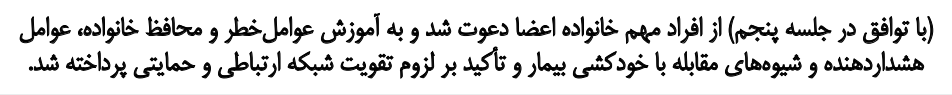 & جلسه ششم" مهاخله كروهى \\
\hline اجراى طرح (مرحله عمل) & 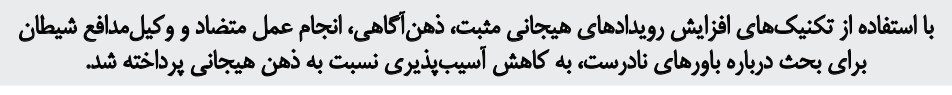 & جلسه هفتمه معاخله كروهى \\
\hline اجراى طُح (مرحله عمل) & در اين جلسه به رهاكردن رنج هيجانى با استفاده از تكنيك نقش بازى كردن مثبت و ABCDE يرداخته شد. & جلسه هشتم مداخله كروهى \\
\hline اجراى طرح (مرحله عمل) & با الامهdABCDE تكنيك و جشيدن للنتها، به زيرسؤالبردن افكار بدبينائه و يادكيرى خوشيينى يرداخته شل. & جلسه نهم مداخله كروهى \\
\hline بايان و ارزشيابي (مرحله عمل) & 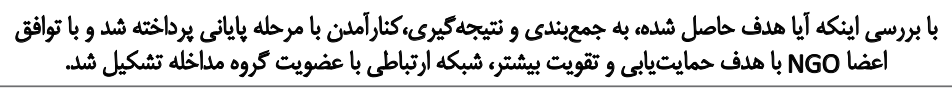 & جلسه دهم مداخله كروهي \\
\hline
\end{tabular}

توانبخننى

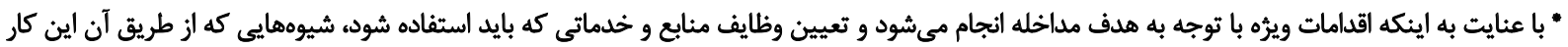

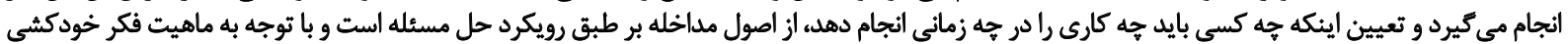

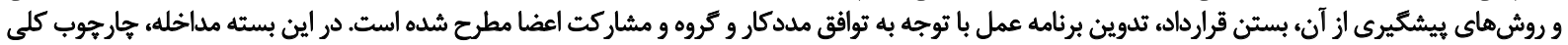

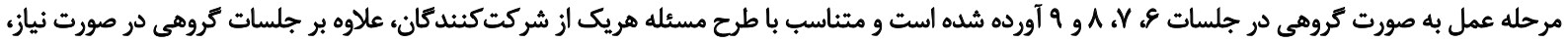

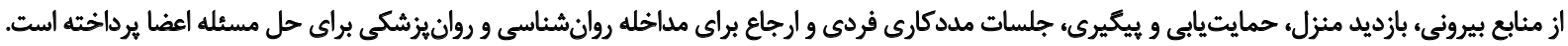


جامعه هدف بود. از آنجايى كه كسانى كه فكر خودكشى دارنده

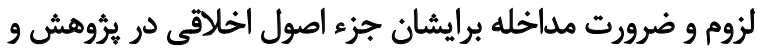

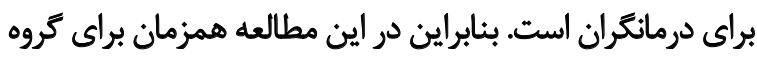

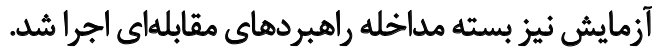

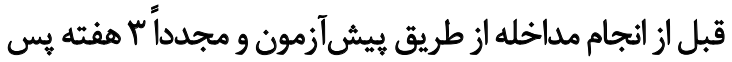

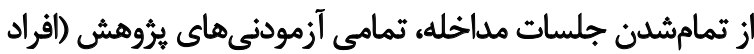

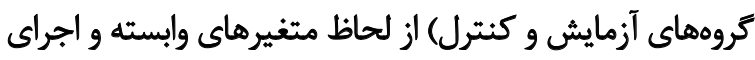

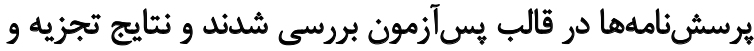

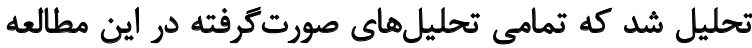

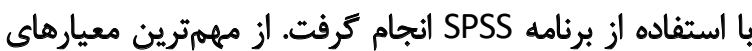

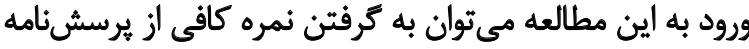

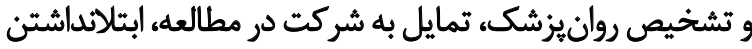

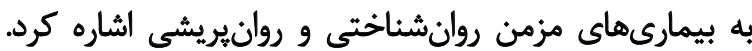

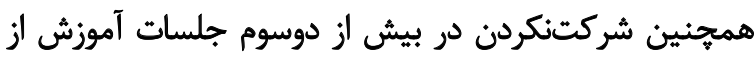
مهمترين معيار هاى خروج از مطالعه بود.

يافتهها

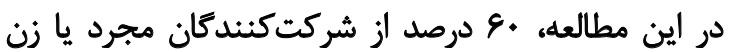

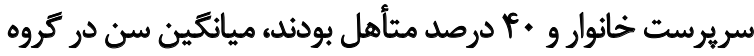

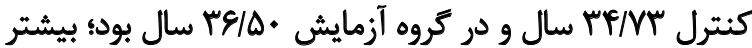

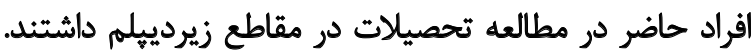

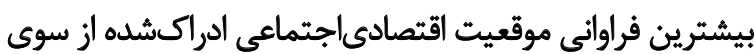

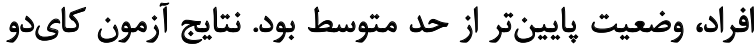

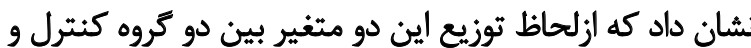

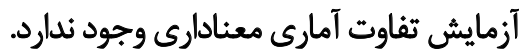
براساس ميانگين نمره بهدستآمده قبل از مداخله ميانگين

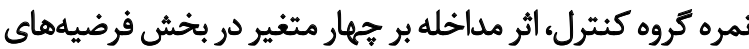

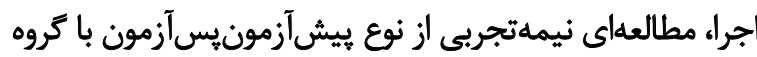

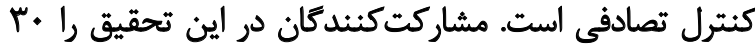

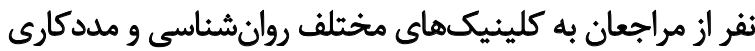

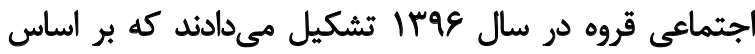

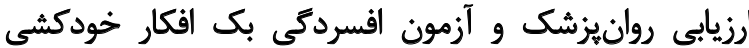

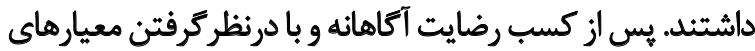

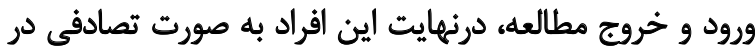

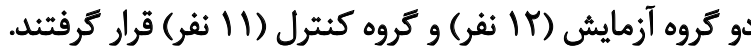

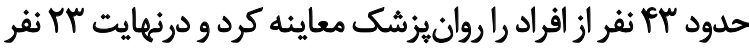

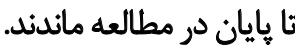

اين مطالعه در بازه زمانى شهريورماه عو تا اوايل دى ماه

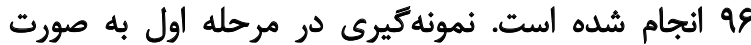

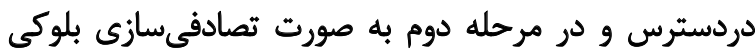

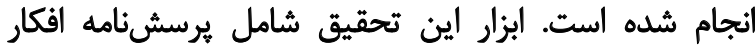

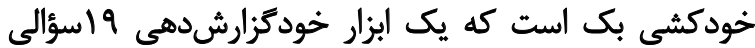

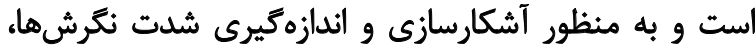

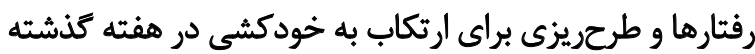

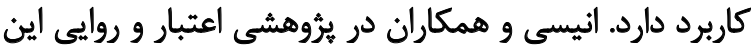

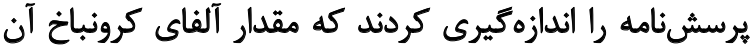

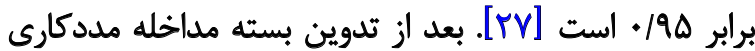

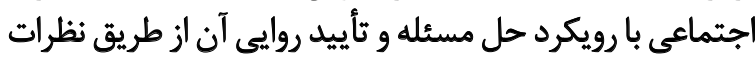

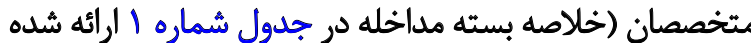

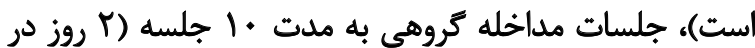

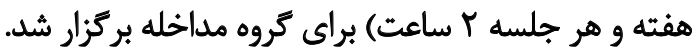
كدهاى اخلاقى مطالعه بعد از تعيين از سوى كميته اخلاق

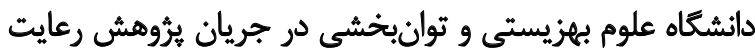

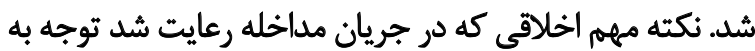

جدول Y. وضعيت متغيرهاى وابسته تحقيق (جهار مؤلفه افكار خودكشى)

\begin{tabular}{|c|c|c|c|c|c|}
\hline اندازه اثر كوهن & نتايج أزمون تى دو نمونه وابسته & ميانكين بعد از مداخله & مياتكين قبل از مداخله & كروه & متغيرهاى وابسته \\
\hline $1 / N 9$ & $\Delta / / \Delta^{*}$ & $\Delta / 91$ & NTE & كروه كتترل & \multirow{2}{*}{ بُعد تمايل به مرى } \\
\hline$\varphi$ & Tr/A9* & $V / M$ & NIV & كروه أزمايش & \\
\hline$V / \Delta 1$ & \&/9." & g/TV & NET & كروه كترل & \multirow{2}{*}{ 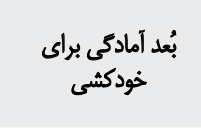 } \\
\hline$\Delta / A V$ & $r / M Y^{\circ}$ & $V \cdot 1$ & NAM & كروه آزمايش & \\
\hline .18 .9 & $1 / M^{*}$ & $r / g r$ & $t / M$ & كروه كتترل & \multirow{2}{*}{ بُعد تمايل به خودكشى } \\
\hline$\Delta / r$ & $1 \% \%$ & - & $\varphi / m$ & كروه آزمايش & \\
\hline$+N+r$ &.$/ 4$ & $M$ & $|/ A|$ & كروه كتبرل & \multirow{2}{*}{ بُعد بازدكشدهماى } \\
\hline$r / \Delta+$ & g/N" & $.1+A$ & $1 / 91$ & كروها آزمايش & \\
\hline
\end{tabular}


جدول ب. تحليل كوواريانس فرضيه اصلى

\begin{tabular}{|c|c|c|c|c|c|c|c|c|}
\hline خطاي معيار & تعديلشيدين & مجذور اتا & Sig. & $\mathbf{F}$ & مياتخين & أزاديه & مجنمورات & Source \\
\hline- & - & .190 & .10 .1 & WWY & ervea & r & $\mid r A T / F q$ & Corrected Model \\
\hline- & - & $.|| Q \mid$ & $.1 \cdot V^{e}$ & $r / \Delta F$ & $\mid r / \cdot q$ & 1 & $1 r / .9$ & Intercept \\
\hline $.1 \Delta \Delta E$ & IV/AF & . TAA & .1 .11 & V/aY & $r V l \cdot G$ & 1 & $\mathrm{rV} / \circ \mathrm{g}$ & نمره ييش أزمون \\
\hline & $T / Y \Delta$ &.$/ 919 q$ & +10.1 & req/ar & ITAS/MT & 1 & ITAS/MT & كروه (آزمايش، كنترل) \\
\hline- & - & - & - & -- & $r / m q$ & r. & $9 V / 91$ & Error \\
\hline- & - & - & - & -- & - & m & rovr & Total \\
\hline - & - & - & - & -- & - & r & $|r \Delta| / \psi$ & Corrected total \\
\hline
\end{tabular}

توانبخننى

است؛ با توجه به نتايج بهدستآمده فرضيه اصلي تحقيق (مداخله

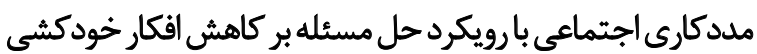

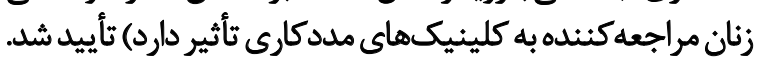

ث

نتايج حاصلشده نشان داد در خردهمقياسهاى تمايل به

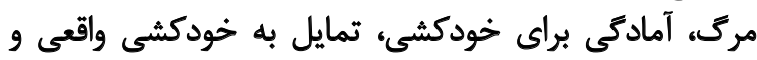

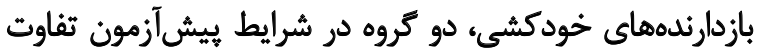

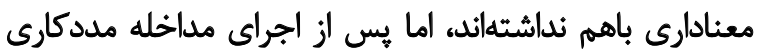

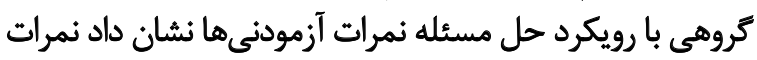

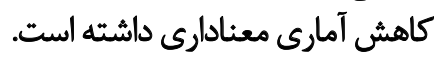

با توجه به معناداربودن جهار فرضيه در جههار مقياس افكار

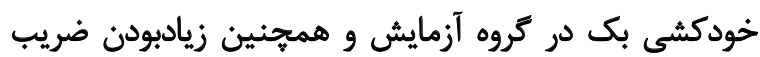

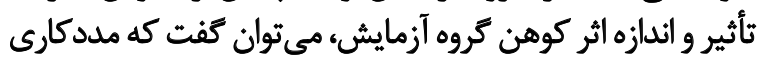

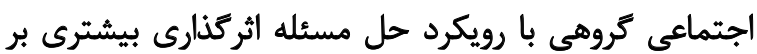

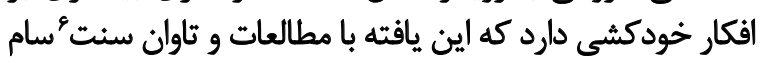

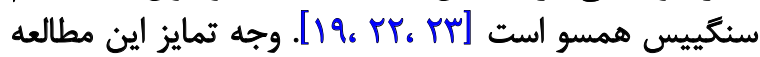
درنظركرفتن شبكه حمايتى و تقويت رابطهها بود، در حالى كه هـ

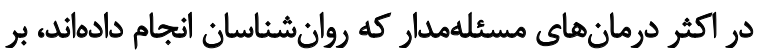

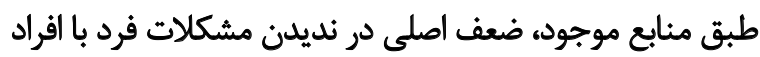
ديكر در ارتباطات است موتئ.

اهم فعاليتهايي كه مددكار اجتماعي براى ثقويت شبكه

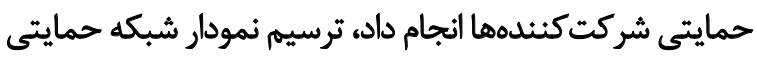

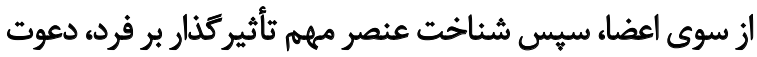

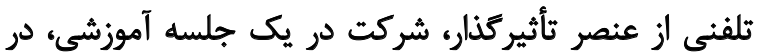

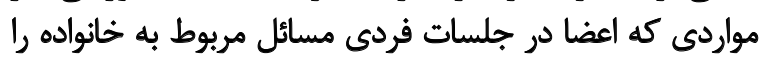

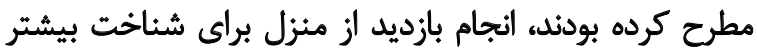

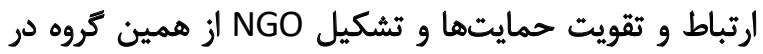

6. Tawn \& evans
تحقيق بررسى شد. همجنين نتايج آزمون تى نشان از معناداربودن

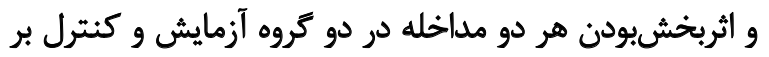

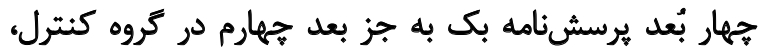

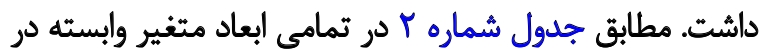

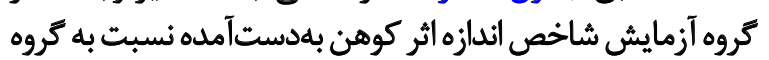

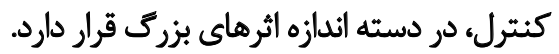
بنابراين براى اينكه عوامل مخدوشگرى قبل از مداخله را

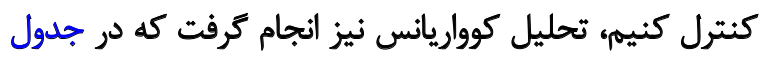

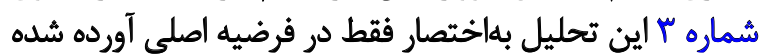

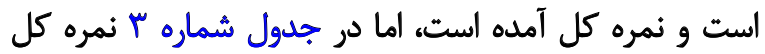

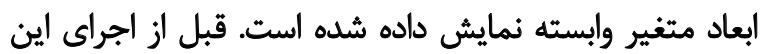

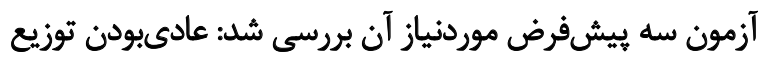

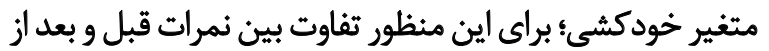

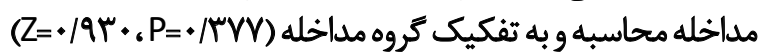

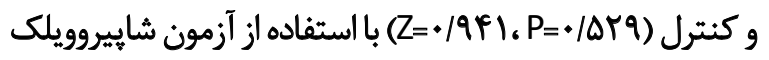

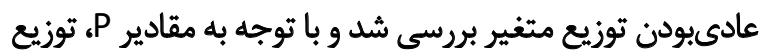

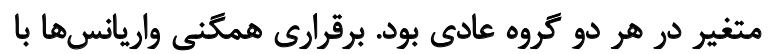

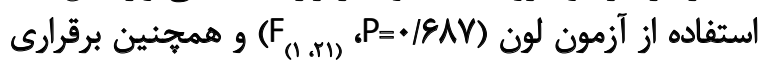

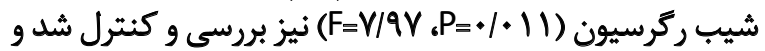
اين دو يهيشفرض نيز برآورده شد.

با توجه به نتايج تحليل كوواريانس مشخصي شُد مداخله

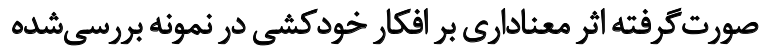

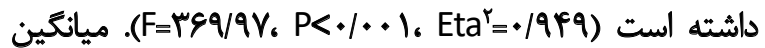

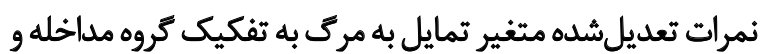

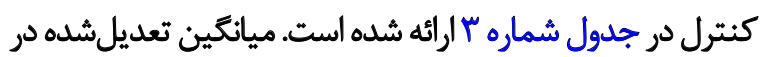

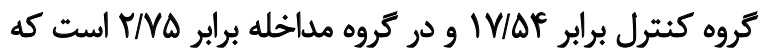

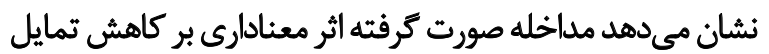

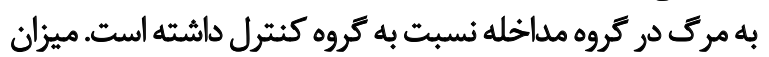

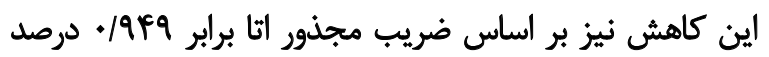


اين شرايط، در حالت آنومى به سر برد، زمينههاى كرايش به

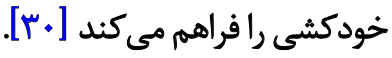

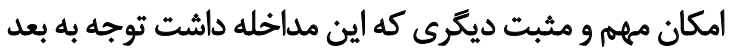

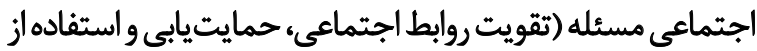

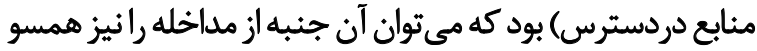

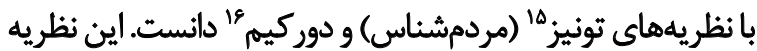

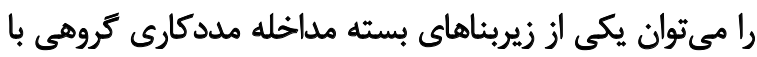

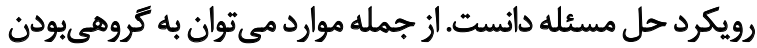

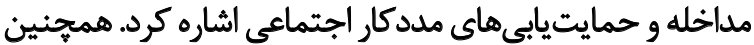

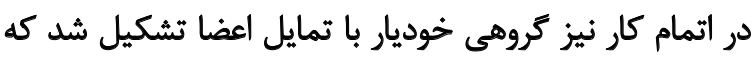

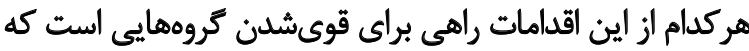

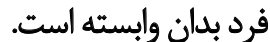

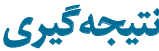

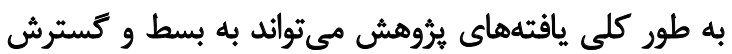

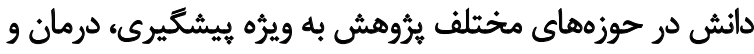

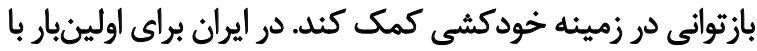

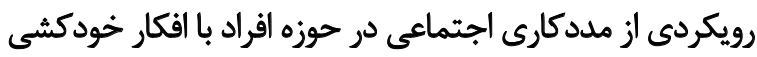

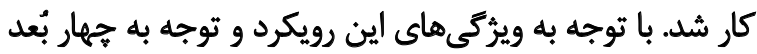

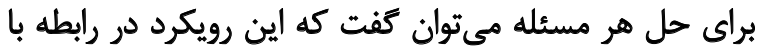

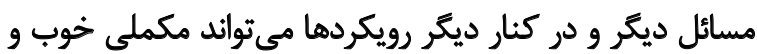

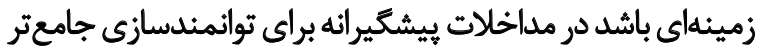
اين دست از مراجعان در معرض آسيب.

با توجه به نتايج اين تحقيق زنانى كه افكار خودكشى دارنده.

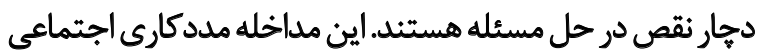

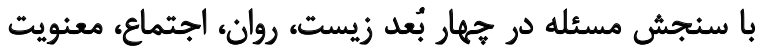

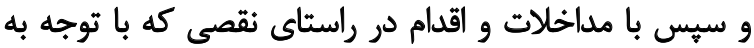

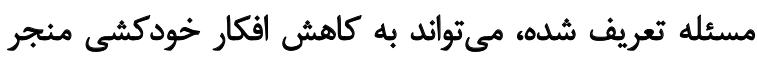

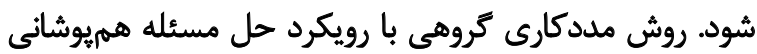

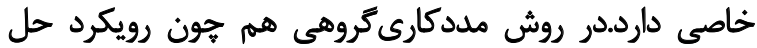

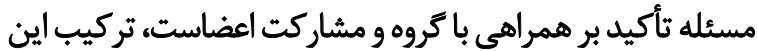

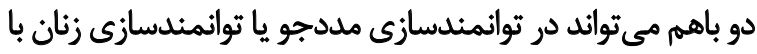

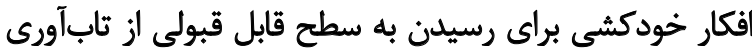

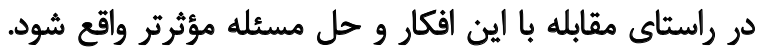

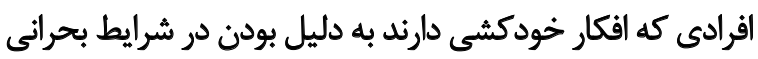

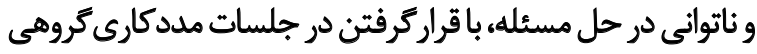

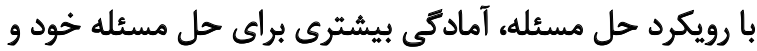
خروج از بحران و كنترل آن را دارند.

در اين مطالعه محدوديتهايى خون دسترسى بـ به نمونهها، داشتن مشكلات بهبودنإيذير، تعهد ضعيف و انجامندادن تكاليف،

15. Tunisia

16. Durkheim
آخر مداخله بود.

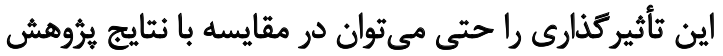

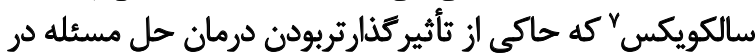

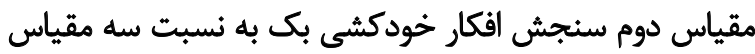

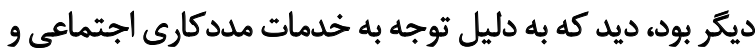

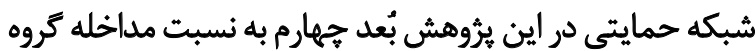

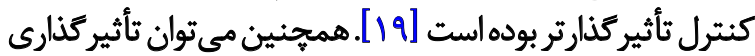

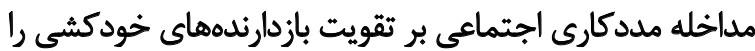

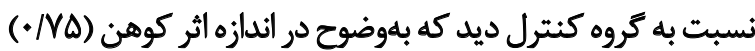

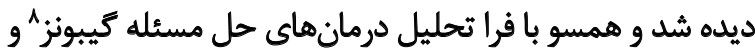
نقش حمايت يابى اجتماعى سلحشورى است.

در اين مطالعه با استفاده از رويكرد حل مسئله در ابتدا به

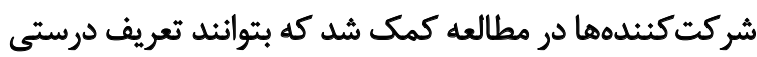

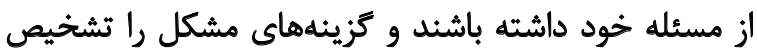

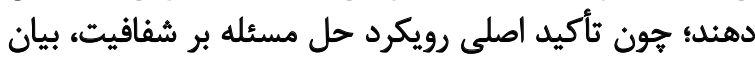

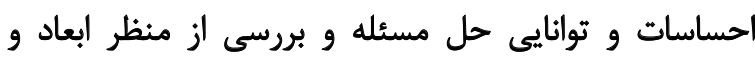

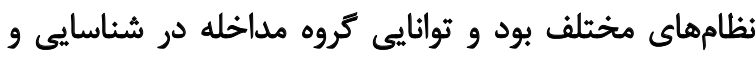

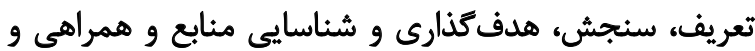

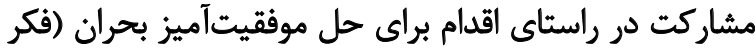

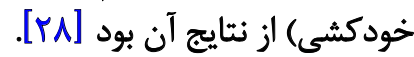

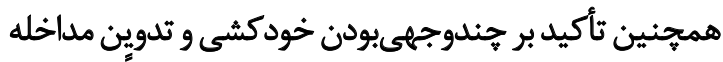

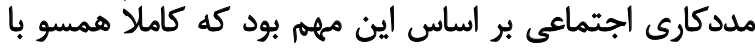

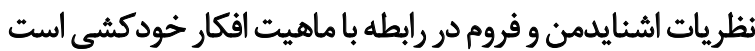

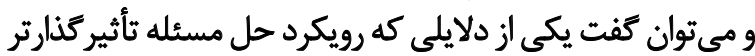

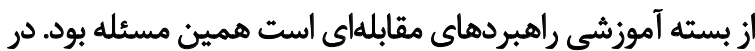

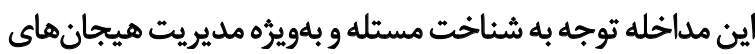

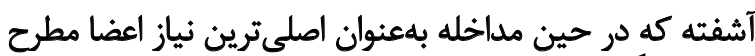

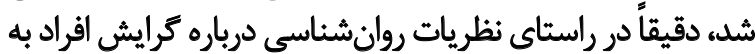

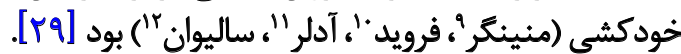
نكتهاي كه در حين جلسات درمانى كار با كروه آزمايش امكان

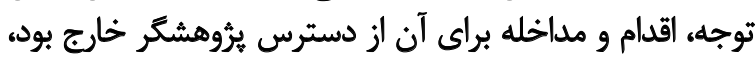

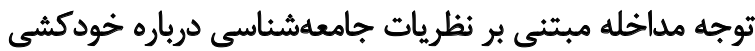

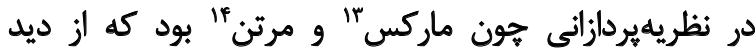

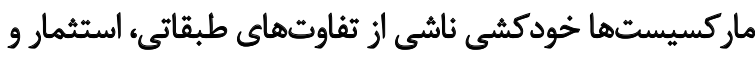

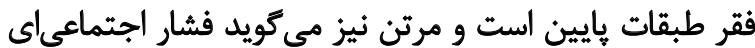

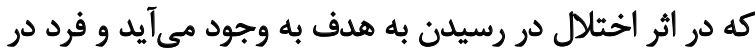

\section{Salkovskis}

8. Gibbons

9. Meinger

10. Freud

11. Adler

12. Sullivan

13.marx

14.Morton 
دانشكاه علوم بهزيستى و توانبخشى بوده است و قبل از انجام

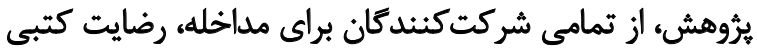

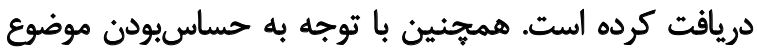

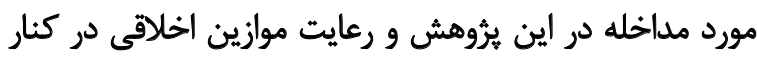

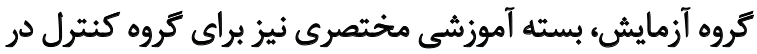

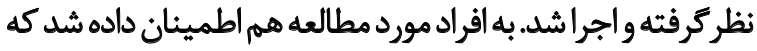

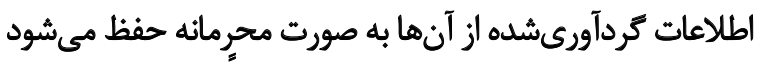

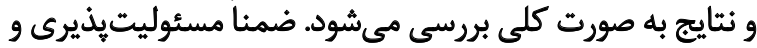

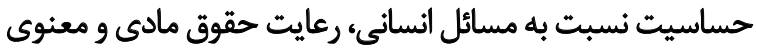
در انتشار نتايج يروهش از جانب محقق رعايت شده است.

$$
\text { مامي مالي }
$$

اين مقاله حاصل ياياننامه كارشناسىارشد نويسنده اول، يرى

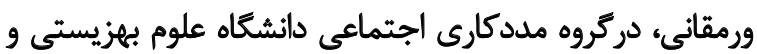
توانبخشى است.

$$
\text { مشار كتن تويسند مان }
$$

تحقيق و جمعآورى دادهاي يثروهش: برى ورمقانى؛ نعارش

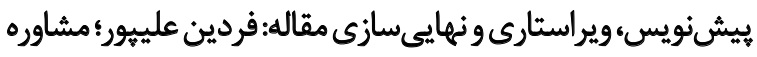

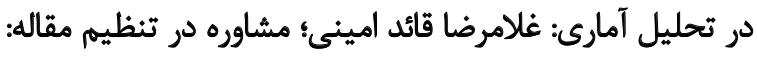

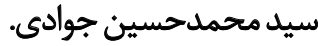

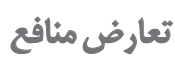

نويسندكان اين مقاله اظهار مىكنئد تعارض منافعى در اين

$$
\text { يثروش وجود ندارد. }
$$

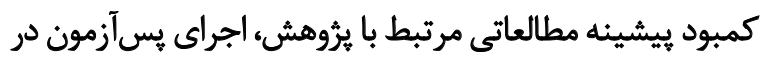

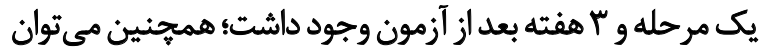

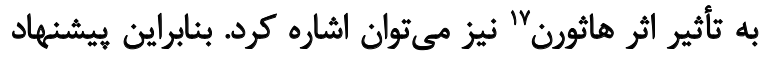

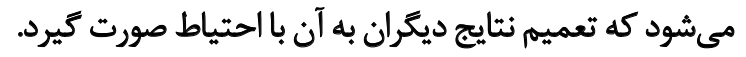

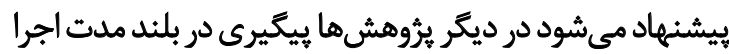

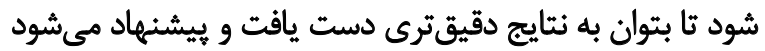

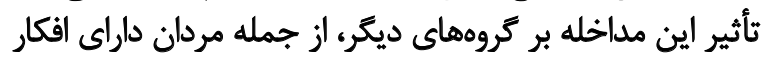

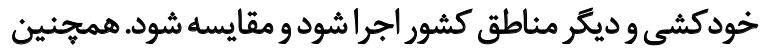

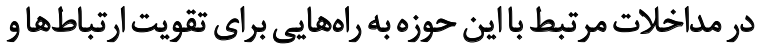

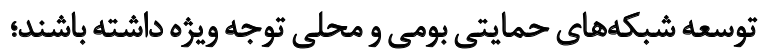

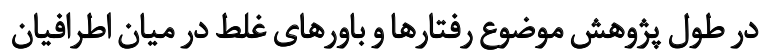

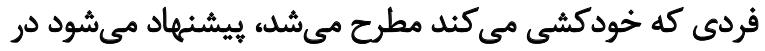

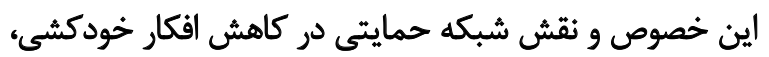

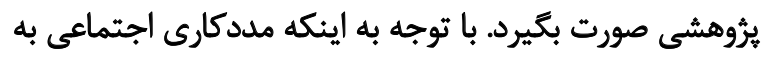

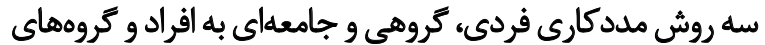

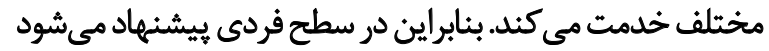

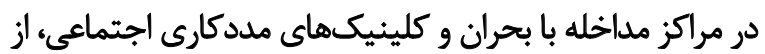

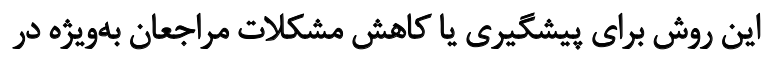
حوزه مديريت خودكشى استفاده شود.

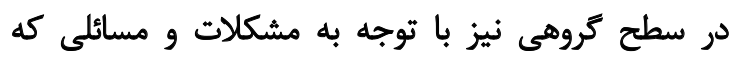

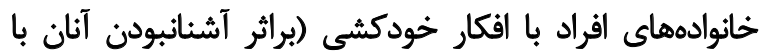

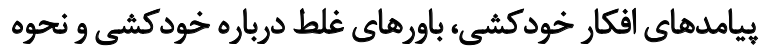

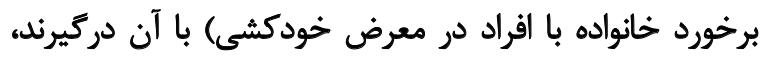

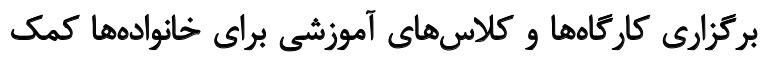

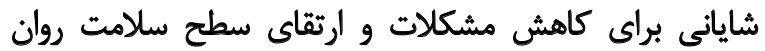

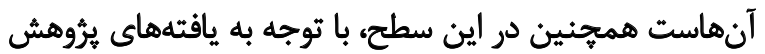

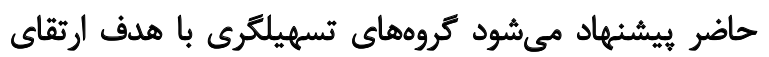

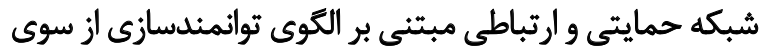

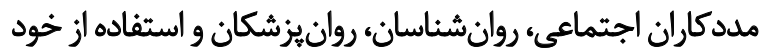

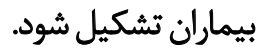

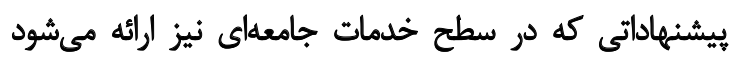

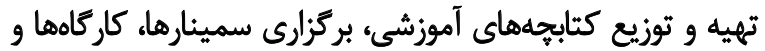

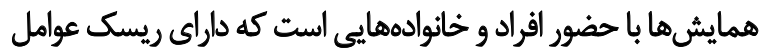

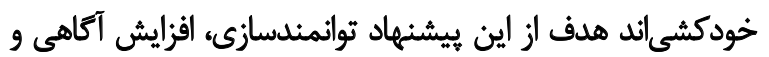

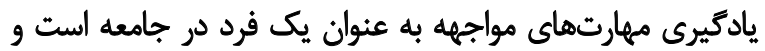

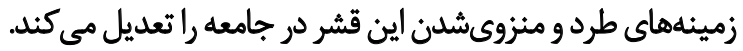

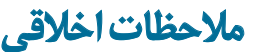
ييروى أز اصول الخلاق يُوهش اين يُروهش با دريافت كد اخلاقى، مورد تأييد كميته اخلاق 


\section{References}

[1] Milner A, McClure R, De Leo D. Globalization and suicide: An ecological study across five regions of the world. Archives of Suicide Research. 2012; 16(3):238-49. [DOI:10.1080/1381111 8.2012.695272] [PMID]

[2] Maple M, Pearce T, Sanford RL, Cerel J. The role of social work in suicide prevention, intervention, and postvention: A scoping review. Australian Social Work. 2017؛ 70(3):289-301. [DOI:10.1 080/0312407X.2016.1213871]

[3] Qureishi SA, Mousavinsab N. [A systematic review of investigations into suicide and attempted suicide in Iran (Persian)]. Iranian Journal of Psychiatry and Clinical Psychology. 2007; 14(2):115-21.

[4] World Health Organization. Preventing suicide: A resource for primary health care workers. Geneva: World Health Organization; 2000.

[5] Carstairs G. Characteristics of the suicide-prone. Thousand Oaks, California: SAGE Publications; 1961.

[6] Khankeh HR, Hosseini SA, Rezaie L, Shakeri J, Schwebel DC. A model to explain suicide by self-immolation among Iranian women: a grounded theory study. Burns. 2015; 41(7):1562-71.

[7] Mofidi N, Ghazinour M, Salander-Renberg E, Richter J. Attitudes towards suicide among Kurdish people in Iran. Social Psychiatry and Psychiatric Epidemiology. 2008; 43(4):291-8. [DOI:10.1007/s00127-007-0296-7] [PMID]

[8] Moyedfar S, Hassan Panah H. [The social factors influencing suicide in Kurdistan Province Youth (Persian)]. Social Issues in Iran. 2010; 1(3):123-44.

[9] Mousavi F, Sajjadi H, Rafiei H, Feizi A. [Familial factors related to attempted suicide (Persian)]. Journal of Social Welfare. 2008; 7(27):53-72

[10] Lavasani F. Brief intervention for suicide management. Tehran: Minister of Health; 1390

[11] Plunkett SW, Henry CS, Knaub PK. Family stressor events, family coping, and adolescent adaptation in farm and ranch families. Adolescence. 1999; 34(133)147-63.

[12] Farrell CT, Bolland JM, Cockerham WC. The role of social support and social context on the incidence of attempted suicide among adolescents living in extremely impoverished communities. Journal of Adolescent Health. 2015; 59-65. [DOI:10.1016/j.jadohealth.2014.08.015] [PMID]

[13] Aminoroaia M, Attari A, Hassanzadeh A. [Research priorities in behavioral sciences from the viewpoint of mental health professionals in Isfahan City (Persian)]. Journal of Psychiatry and Clinical Psychology of Iran. 2010; 16(2):127-34.

[14] Kadivar P, Zahedi F. [Crisis coping styles and attempted suicide in female students (Persian)]. Journal of Social Welfare. 2007; 6(25):111-32.

[15] Feldman BN, Freedenthal S. Social work education in suicide intervention and prevention: An unmet need? Suicide and Life-Threatening Behavior. 2006; 36(4):2-7. [DOI:10.1521/ suli.2006.36.4.467] [PMID]
[16] Safizadeh F. Suicide from the perspective of psychology Tehran: Iran Jaam; 2011

[17] Compton BR, Galaway B. Social work processes. Belmont, California: Wadsworth Pub; 1999.

[18] Sucato V. The problem-solving process in short-term and long-term service. Social Service Review. 1978; 52(2):244-64. [DOI:10.1086/643621]

[19] Choi NG, Marti CN, Conwell Y. Effect of problem-solving therapy on depressed low_income homebound older adults' death/suicidal ideation and hopelessness. Suicide and LifeThreatening Behavior. 2016; 46(3):323-36. [DOI:10.1111/ sltb.12195] [AMID] [PMCID]

[20] Linehan MM, Camper P, Chiles JA, Strosahl K, Shearin E. Interpersonal problem solving and parasuicide. Cognitive therapy and research. 1987; 11(1):1-12. [DOI:10.1007/ BF01183128]

[21] Salkovskis PM, Atha C, Storer D. Cognitive-behavioura problem solving in the treatment of patients who repeatedly attempt suicide a controlled trial. The British Journal of Psychiatry. 1990; 157(6):11-6. [DOI:10.1192/bjp.157.6.871]

[22] Sangeeth S. Application of perlman's problem solving mode in casework with marginalised elderly. Journal of Nursing and Health Science. 2016; 5(1):35-45. [DOI: 10.9790/195905123545]

[23] Townsend E, Hawton K, Altman DG, Arensman E, Gunnell $D$, Hazell $P$, et al. The efficacy of problem-solving treatments after deliberate self-harm: Meta-analysis of randomized controlled trials with respect to depression, hopelessness and improvement in problems. Psychological Medicine. 2001 31(6):979-88. [DOI:10.1017/S0033291701004238]

[24] Soltani S., Mikaeli F. [Comparison of the effect of metacognitive therapy and problem-based treatment on reducing social anxiety in urmia university students (Persian)] Journal of Psychology (Tabriz University). 2012; 7(28):89-100.

[25] Mowlavi P, Abbasi-RanjbarV, Mohammad-Nia H. [Assessment of suicide risk factors among attempted suicide in Ardebil within first half of 2003 (Persian)]. Journal of Rehabilitation. 2007; 8(1).

[26] Valikhani A, Aflakseir A, Hashemi R, Fathi M, Momeni H, Abbasi Z. [The relationship between personality characteristics and early maladaptive schema with suicide ideation in Iranian late adolescents (Persian)]. Practice in Clinical Psychology. 2017; 5(4):271-80. [DOI:10.29252/nirp.jpcp.5.4.271]

[27] Anisi G, Fathi Ashtiani A, Salimi Sh, Ahmadi Nodeh Kh. Validity and reliability of Beck Suicide Scale Ideation (BSSI) among soldiers. Journal of Military Medicine. 2005; 7(1):33-7.

[28] Perlman H. Social casework: A problem-solving process. Chicago: University of Chicago Press; 1957.

[29] Forum, E. The true nature of man [F, Javid, Persian trans.] Tehran: Akhtaran; 2006.

[30] Ritzer G. Sociological theory: 2 Pennsylvania Plaza New York City: Tata McGraw-Hill Education; 1996. 
This Page Intentionally Left Blank 